\title{
Modified endoscopic septoplasty: a novel technique
}

\author{
Abstract \\ Introduction: Septal deviation is a commonly found structural malformation causing \\ blockade of one or both nostrils, frequent sinusitis, headache, postnasal drip, nasal \\ bleeding, and noisy breathing during sleep etc. Corrective surgery for deviations of \\ the nasal septum remains a challenge to even experienced Otorhinolaryngologists. \\ Endoscopes are being widely used to achieve better results with this commonly \\ performed procedure.
}

Materials and methods: 258 cases ( 178 males and 80 females) over a period of five years from 2008 to 2013 with septal deviation and nasal obstruction were included in our study. All the cases underwent endoscopic septoplasty under general anesthesia. With proper daily nasal care, the time to recover post operatively was around 2- 3 weeks. The patients were followed up to one year post- operatively.

Results: Nasal obstruction was the most common presenting symptom in $155(60.07 \%)$ patients. In all the 258 cases studied, endoscopic septoplasty was performed as the primary procedure. No major complications occurred in the immediate post- operative period. Minor complications like haematoma and haemorrhage were encountered in two patients.

All the cases had good postoperative relief from nasal obstruction. This paper describes the technique of modified endoscopic septoplasty as performed by us at our institute.

Conclusion: With our wide experience, we have refined this novel technique of septoplasty. It has greatly reduced the rate of complications like synechiae, septal perforation and improved surgical outcomes.

Keywords: endoscopic septoplasty, septal window, deviated nasal septum
Volume 10 Issue 4 - 2018

\author{
Tiruchy Narayanan Janakiram, Samavedam \\ Udaya Chanukya, Shilpee Bhatia Sharma, \\ Hina Baxi \\ Department of ENT \& HNS, Royal Pearl Hospital, India
}

Correspondence: Tiruchy Narayanan Janakiram, Head of the Department ,Department of ENT \& HNS, Royal Pearl Hospital ,C 12 3RD Cross East, Thillai Nagar, Trichy 620018 Tamil Nadu, India, Tel 984246I I76, Email tnjanakiram777@gmail.com

Received: October 15, 2016 | Published: July 03, 2018

\section{Introduction}

Septal surgeries have come a long way from their inception. They have evolved from being primitive, aggressive procedures towards procedures with better results and less morbidity to the nasal function due to surgical trauma. Endoscopic septoplasty is being widely practiced worldwide nowadays.

The use of nasal endoscopes in rhinological practice has revolutionized the diagnosis and treatment of nasal obstruction. The nasal endoscope allows precise preoperative identification of the septal pathology and associated lateral wall abnormalities and helps in better planning of endoscopic aided surgery. ${ }^{1}$ Use of endoscopes for septal correction was first described in 1991 by Lanza et al., ${ }^{2}$ and Stammberger. ${ }^{3}$ Endoscopic septoplasty is a minimal invasive technique that can limit the dissection and minimize trauma to nasal septal flap under excellent visualization. This is reported to be especially valuable for patients who have had previous septal surgery.,

\section{Case presentation}

In this paper, we describe our technique of endoscopic septoplasty. We have operated on 258 cases from 2008 to 2013 among whom 178 $(68.9 \%)$ were males and $80(31.1 \%)$ were females.

We follow a standard protocol for all cases. All patients with chronic nasal obstruction of over 3 months duration caused by deviated nasal septum underwent septoplasty by endoscopic method only. Patients are counseled pre-operatively regarding the procedure including its complications and written informed consent is obtained.
Pre-operative laboratory work up comprises of a complete hemogram. Surgery is always performed under General anesthesia (G.A) unless patient is deemed unfit for GA during the pre-anesthetic consultation.

The nasal cavities are packed on both the sides with ribbon gauze soaked in a solution of 1:1000 adrenaline using a 0 degree, $4 \mathrm{~mm}$, $18 \mathrm{~cm}$ wide angled endoscope ( Karl Storz).

Nasal Endoscopy is done to assess the septal deviation and spurs (Figure 1) ( Figure 2). Septal infiltration is carried out with a solution of $2 \%$ Xylocaine with 1: 100,000 adrenaline in the sub-mucosal plane. It is given with a single prick at the inferior most part of the nasal septum at the junction of the septum with the floor of the nasal cavity anterior to the mucocutaneous junction. The infiltration is given at the same point on both the sides (Figure 3). The incision is always given on the deviated side. It is given anterior to the mucocutaneous junction because the skin present at that place is thick and chance of a tear of the flap is less (Figure 4). The mucoperichondrial flap is raised on the deviated side with a Freer's elevator strictly under vision. The flap is not to be raised beyond the deviated part because the part of the septum posterior to the deviation is not under direct vision (Figure 5) (Figure 6). The caudal end of the septum is then palpated and an incision is given on the cartilage $1 \mathrm{~cm}$ behind the columella. This $1 \mathrm{~cm}$ of the cartilage is saved to prevent post operative tip deformities (Figure 7). The cartilage is sliced and the opposite side is entered, the mucoperichondrial flap of the opposite side is then elevated with a Freer's elevator. A cut is given in the septal cartilage as high as possible. A septal window is created and a Ballenger's swivel knife is taken and lodged in the place where the cartilage was cut. Creation 
of a septal window thus increases the area of exposure (Figure 8) (Figure 9). The flap on the non-deviated side is elevated till the bonycartilaginous junction.

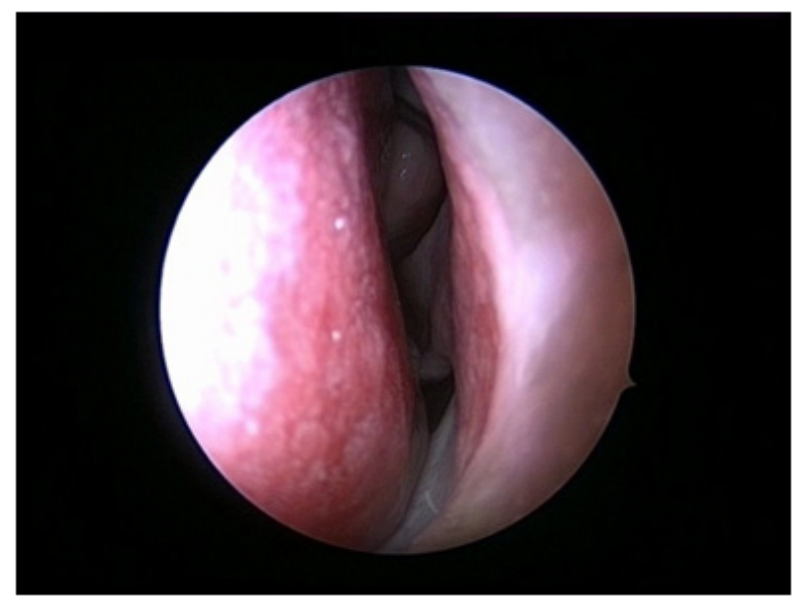

Figure I Deviation of septum to left side.

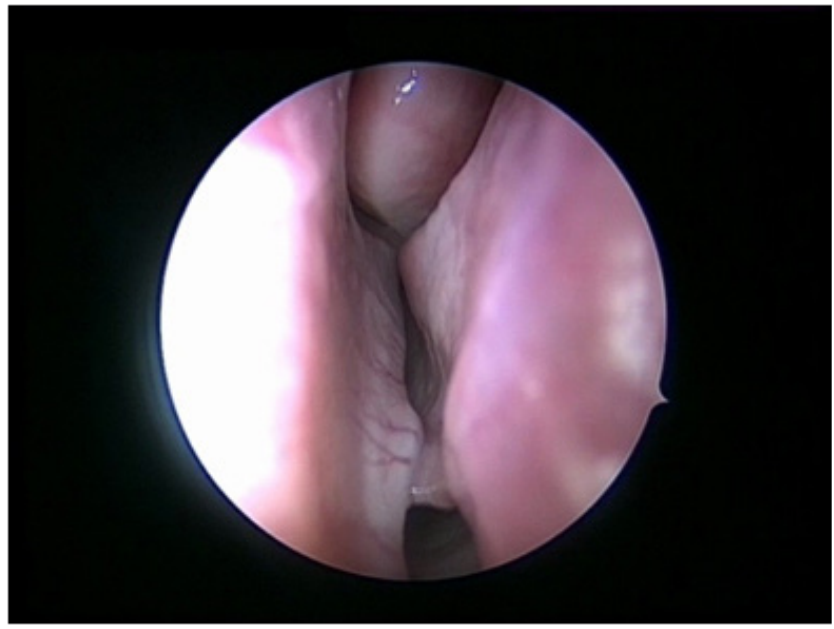

Figure 2 Spur present towards left side.

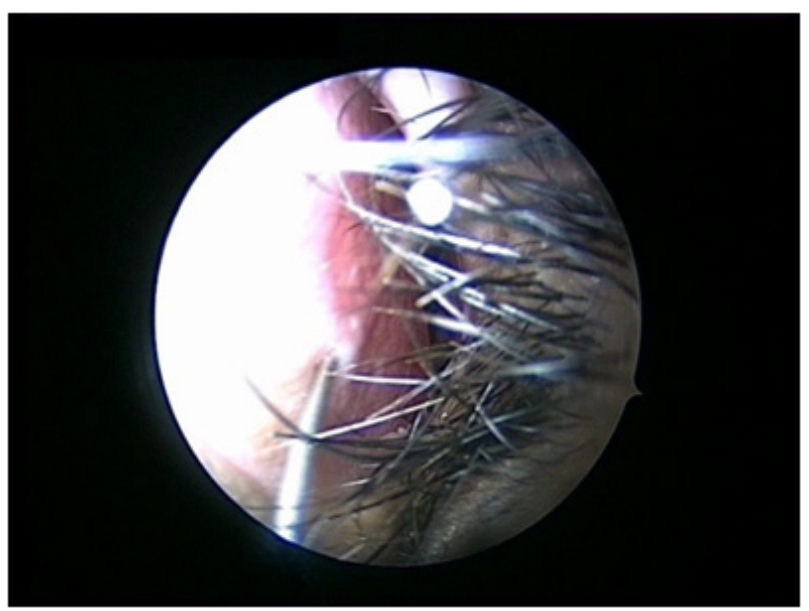

Figure 3 Infitration.

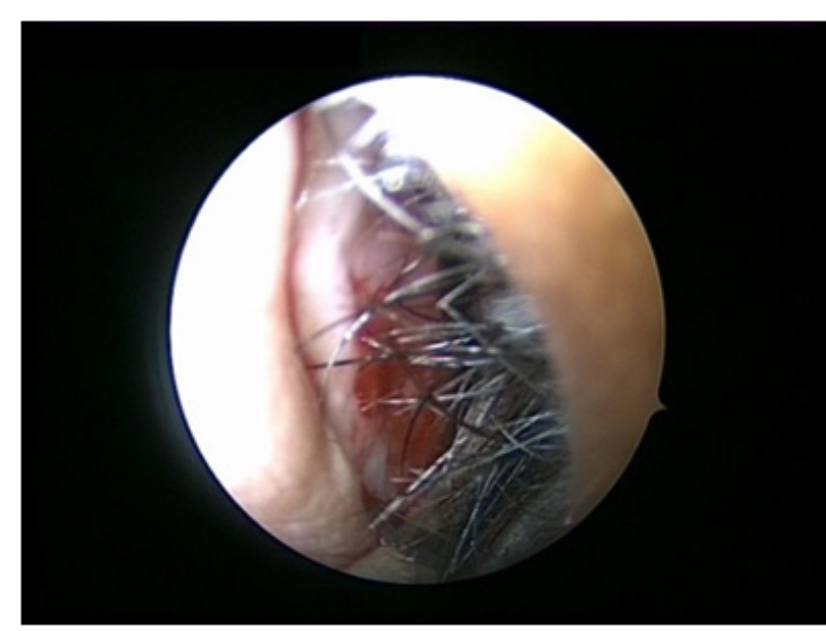

Figure 4 Skin incision.

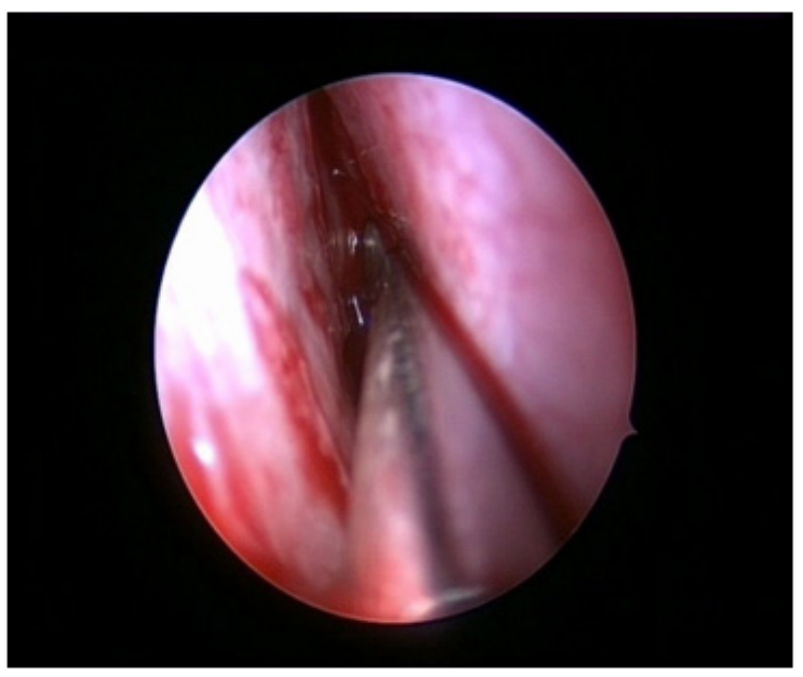

Figure 5 Elevation of flap on left side.

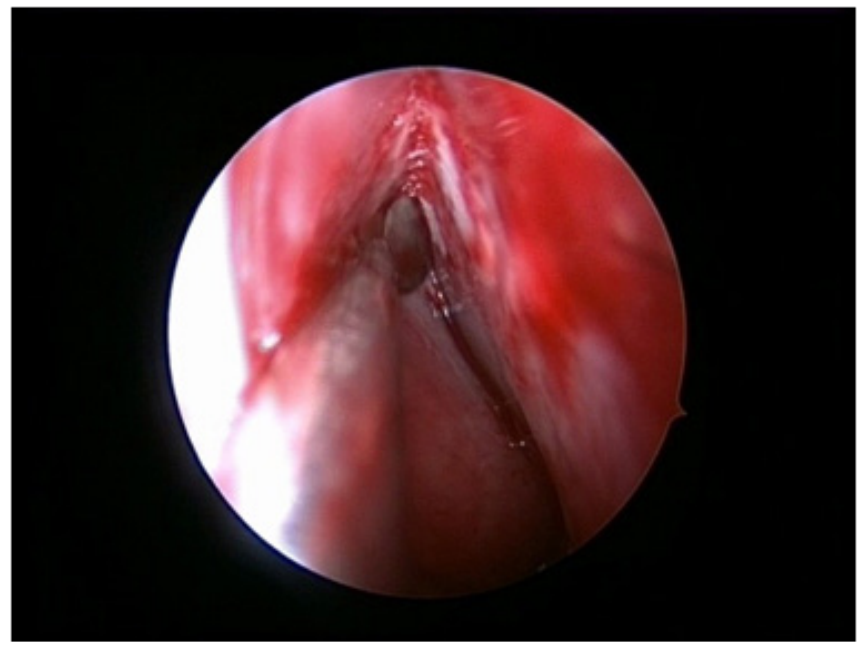

Figure 6 Elevation of the non-deviated side. 


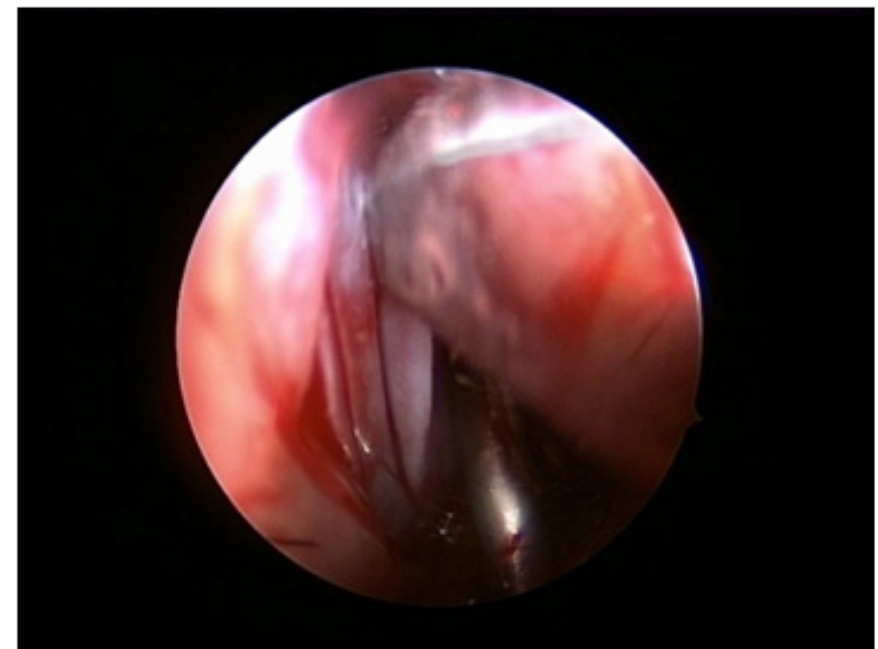

Figure 7 Cartilage incision.

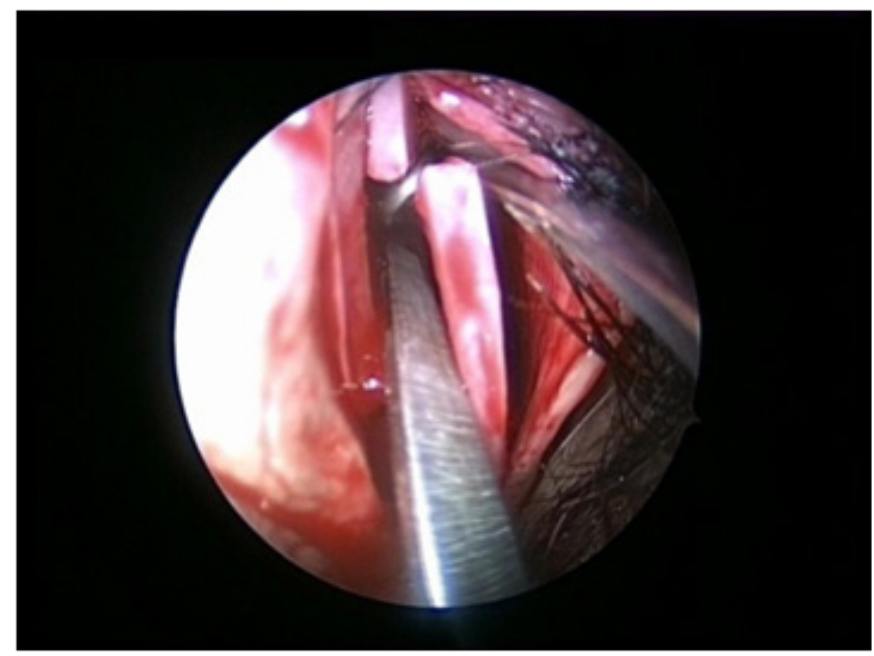

Figure 8 Ballenger's knife- septal window.

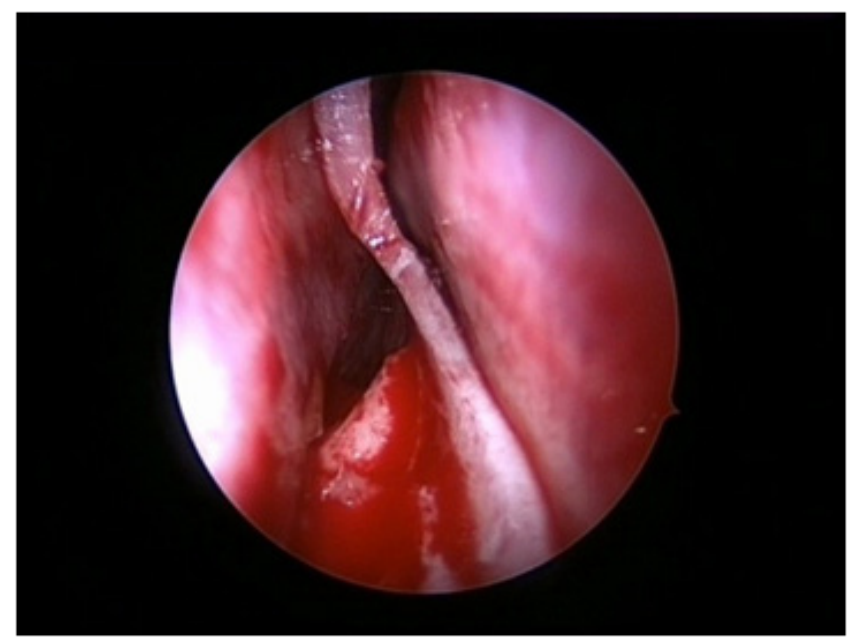

Figure 9 Exposure after septal window.
After reaching the bony-cartilaginous junction, the flap is elevated downwards towards the floor. The elevation is done from posterior to anterior direction. This makes the flap on the non-deviated side safe. The Freer's elevator is placed in the bony-cartilaginous junction and the inferior strip of cartilage is sliced off from the maxillary crest from posterior to anterior direction. The strip of cartilage is gently swung out. In case of any spur, bony or cartilaginous, the flap over the spur is never elevated directly. The cartilage/bone above the spur is cut at multiple levels and the pieces are removed with the help of a Blakesley's forceps. The Freer's elevator is placed between the spur and the flap and the spur is gently pushed to the non-deviated side and is removed with the Blakesley's forceps (Figure 10). In case of any deviation or spur from the maxillary crest, it is chiseled out. The direction of the chisel is always towards the maxillary crest only. The flaps are repositioned and a diagnostic nasal endoscopy is done to assess the patency of the nasal cavities. Nasal packing is done using commercially available sponge packs made from crosslinked polyvinyl alcohol (Merocel®) using a Thudicum's nasal speculum, in order to prevent the reflection of the flap at the incision site. The immediate post-operative management includes intravenous antibiotics and analgesics. Nasal pack is removed on the second day after surgery and patients are advised oral antibiotics, analgesics, anti-histaminics and decongestant nasal drops for one week. Patient is advised saline nasal douching for a week and discharged on the second day after surgery with a prescription of oral antibiotics, antihistaminics and decongestant nasal drops for one week. Saline nasal drops are given for two weeks after surgery.

A total number of 258 patients underwent modified endoscopic septoplasty over a period of five years from 2008 to 2013. Among these 258 patients, $178(68.9 \%)$ were males and $80(31.1 \%)$ were females. The age of the patients ranged from 18 to 45 years with the average being 31.5 years.

Nasal obstruction was the most common presenting complaint found in about 155 patients. The duration of the presenting complaints varied from four months to 6 years.

All the patients were treated medically before surgery with topical steroid sprays and antihistamines. Diagnostic nasal endoscopy was done for all the patients pre- operatively with diagnostic nasal endoscopy. Our study found no major complications intra operatively and in the immediate post- operative periods. Minor complications, such as haemorrhage and hematoma were seen in one patient each.

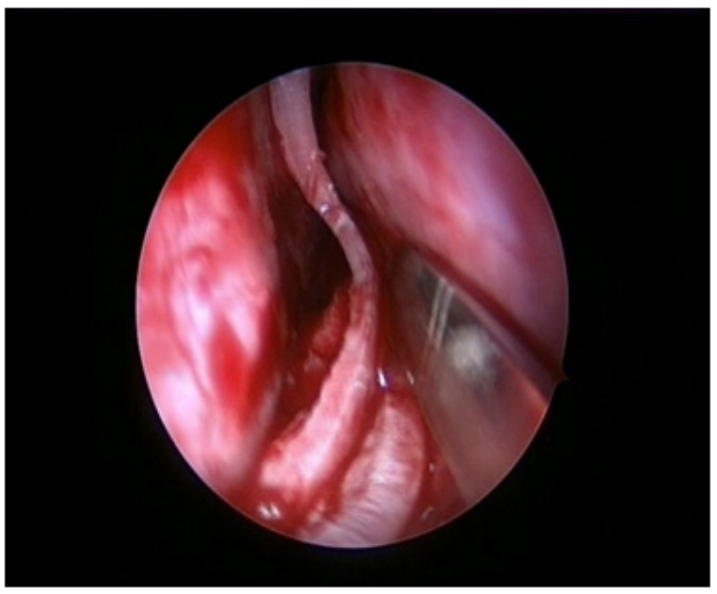

Figure I 0 Removal of the spur. 


\section{Discussion}

Septoplasty is a standard procedure in the practice of otorhinolaryngology aimed at relieving nasal obstruction. The rationale behind devising an endoscopic technique from a conventional 'headlight' approach is to improve the visibility for achieving complete correction of the deviation with minimal injury to the surrounding structures, thus improving surgical outcome.

Endoscopy aids the surgeon to localize the deviation and spurs under direct visualization. Correction of the deviation under endoscopic visualization enables the surgeon to achieve complete correction.

Endoscopic septoplasty has already been described by other authors, ${ }^{1,6-8}$ but not much of emphasis was given on how to deal in areas like acute spurs and deviations, where the mucoperichondrial flap is very much vulnerable to tear during elevation.

This technique of endoscopic septoplasty is different from that described in literature. Infiltration is given with a single prick on each side. Avoiding multiple points of infiltration facilitates a clear field inside the nasal cavity. The incision is placed in the skin, making it less vulnerable to tear. It is always give on the convex side which is easier. The flap is not elevated beyond vision and thus possibility of a flap tear is much less. Creation of a septal working window increases the exposure and creates room for instrumentation. It is also helpful in assessing the deviation of the posterior part of the septum. The removal of spur by pushing it to the opposite flap avoids the tear on the side of the spur. All these steps in our technique make it a novel technique. The complications encountered are very minimal and patients report excellent relief of symptoms post-operatively. The technique can be used with success in revision cases as well.

\section{Acknowledgments}

None.

\section{Conflict of interest}

There are no financial interests or any conflict of interest.

\section{References}

1. Nayak DR, Balakrishnan R, Murthy KD. An endoscopic approach to the deviated nasal septum- a preliminary study. J Laryngol Otol. 1998;112(10):934-39.

2. Lanza DC, Kennedy DW, Zinreich SJ. Nasal endoscopy and its surgical applications. In: Lee KJ, editor. Essential otolaryngology: head and neck surgery. 5th ed. New York: Medical Examination Publ; 1991. Co. 373-87.

3. Stammberger H, Hasler G. Functional endoscopic sinus surgery the Messerklinger technique. Philadelphia: BC Decker; 1991. 432-433 p.

4. Hwang PH, Mc Laughlin RB, Lanza DC, et al. Endoscopic SeptoplastyIndications, technique and results. Otolayngol Head Neck Surg. 1999;120(5):678-82.

5. Chung BJ, Batra PS, Citradi MJ, et al. Endoscopic Septoplasty revisitation of the technique, indications and outcomes. Am J Rhinol. 2007;21(3): 307-11.

6. De Sousa A, Inciartef L, Levine H. Powered endoscopic nasal septal surgery. Acta Med Port. 2005;18(4):249-56.

7. Raynor E. Powered endoscopic septoplasty for septal deviation and isolated spurs. Arch Facial Plast Surg. 2005;7(6):410-2.

8. Sindwani R, Wright ED. Role of endoscopic septoplasty in the treatment of atypical facial pain. J Otolaryngol. 2003;32(2):77-80. 